\title{
Treatment of piriformis syndrome with oxygen-ozone therapy
}

\author{
Luigi Valdenassi, ${ }^{1,2}$ Debora Bellardii ${ }^{2,3}$ \\ ${ }^{1}$ Department of Internal Medicine and Medical Therapy, University of Pavia; ${ }^{2}$ Scientific Society of Oxygen Ozone \\ Therapy, Gorle (BG); ${ }^{3}$ Radiodiagnostic Expert, Italy
}

\begin{abstract}
Piriformis syndrome is a pain-causing disease of the sciatalgic type, also called false sciatalgia. Indeed, it is possible that a suffering of this muscle, caused by different etiologies, is responsible for a more or less pronounced sciatalgic pain. All this in the absence of overtly pathological problems such as a disc hernia, a canalized stenosis or a mass in a ischio-crural region. We dealt with this problem in a group of patients who had been submitted to various therapies in the immediately preceding periods: pharmacology, tecartherapy and manual physiotherapy. After these treatments, these subjects had the same painful symptoms without any improvement. Therefore, they were treated with oxygen ozone by infiltration. Evaluation according to the visual analog scale, baropodometric examination and clinical trials of Freiberg and Page and Nagle were performed before, in the middle, and at the end of the treatment. The results were very encouraging, showing a noticeable improvement until the disappearance of symptoms.
\end{abstract}

\section{Introduction}

Piriformis syndrome is a sometimes-unknown cause of pain localized in the gluteus, hip, with frequent irradiation to the back portion of the thigh. Literature data show how responsible it can be of sciatalgia syndrome. ${ }^{1,2}$

Symptomatology results from sciatic nerve compression in the stomach of the muscle itself. Indeed, the sciatic nerve emerges from the pelvis through a single trunk, which in most cases passes

Correspondence: Luigi Valdenassi, Scientific Society of Oxygen Ozone Therapy, via Roma 69, 24020 Gorle (BG), Italy.

E-mail: info@ossigenoozono.it

Key words: Piriformis syndrome; Treatment; Oxygen-ozone therapy.

Received for publication: 11 December 2017.

Accepted for publication: 14 December 2017.

(C) Copyright L. Valdenassi and D. Bellardi, 2017

Licensee PAGEPress, Italy

Ozone Therapy 2017; 2:7234

doi:10.4081/ozone.2017.7234

This article is distributed under the terms of the Creative Commons Attribution Noncommercial License (by-nc 4.0) which permits any noncommercial use, distribution, and reproduction in any medium, provided the original author(s) and source are credited. before the piriformis muscle, whereas in $15 \%$ of cases it crosses the piriformis or divides into a tibial and a peroneal branch running from the front, back or through the muscle. ${ }^{3,4}$

By itself the piriformis muscle is thin, initially flattened, and then it assumes a roundish shape.

It is made up of 3 beams that originate from the 2nd and $3 \mathrm{rd}$ sacral foramen. It is in the following position both inside and outside the pelvis, has a function substantially of external rotation, with a slight abduction and extension component, and stabilizes the femur during the resting phases, preventing the femur from rotating inside. ${ }^{5-7}$

In relation to its function, it can be subject to hypertrophic phenomena and stiffening that may trigger the so-called piriformis syndrome.

This pathology causes a sciatalgic pain in the absence of a disease to the column. Symptomatology may result from the compression of the sciatic against the bony arch of the greater sciatic foramen or, of the bottleneck of the same nerve inside the muscle. 5,8

Etiology is multifactorial; often the most common cause is traumatic-type. Other causes are dysmetria of the lower limbs, myositis of the piriformis muscle, or the outcome of hip surgery. 4,9

Pain is often accompanied by paresthesia of the lumbar tract, the buttocks, in the posterior areas of the leg, thigh and thigh and the plant of the foot.

Movement deficits may arise, as well as reduced sensitivity in some areas of the lower limbs and swelling in the area from sacrum to greater trochanter.

Symptomatology is exacerbated if the subject sits for a long time with the internal rotation of the femur or after sports and work activities.

Diagnosis is carried out by clinical examination and instrumental examinations: electromyography, computed tomography and magnetic resonance.

There are two specific clinical trials used in the diagnostic phase. First, Freiber test. In this case, the patient is prone, passively flexing the knee at $90^{\circ}$, bringing the leg outwards, leading to an internal rotation of the femur: if stretching of the muscle causes pain it is considered as positive. Second, Peace and Nagle test. In this case, the seated patient goes into abduction-extra isometric rotation of the hips against the hands of the doctor.

The piriformis muscle, if its diameter increases, causes myofascial and compressive pain.

\section{Materials and Methods}

Piriformis syndrome is usually treated in different ways: pharmacologically, by taking NSAIDs and muscle relaxants, orinoculation of Botulinum type A toxin and injections of local anesthetic drugs and corticosteroids; through instrumental physical therapies 
by ultrasound and techartherapy; through manual physical therapies by stretching and deep transverse massages. Oxygen ozone therapy is successfully practiced in the treatment of sciatica and low back pain due to radicular disc conflicts and to disc hernias.

It has been highlighted how even in the case of piriformis syndrome or where there is no involvement of the column, improvements in symptomatology have been observed. For this reason, we have tried to codify the infiltration technique of the oxygen ozone therapy in the piriformis syndrome with a precise, standardizable and repeatable method. ${ }^{10-13}$

Two points have been identified.

Using the upper edge of the great trochanter as main landmark, the needle is directed parallel to the horizontal plane, in medial-lateral direction towards the 2 nd and 3 rd sacral foramen.

Using the ischiatic tuberosity as landmark, the needle is directed caudal-cranially parallel to the horizontal plane.

We preferred to use a mixture of oxygen-ozone first because of its powerful anti-inflammatory activity; in addition because the gaseous mass, unlike drugs that are injected in liquid form, better spreads over the surrounding fibers, creating a detachment among these, favored by the recovery of microcirculation determined by the ozone itself. ${ }^{14,15}$

Moreover, because the location varies according to the morphological structure of the patient, these objective inaccuracies are better remedied through a gaseous material. ${ }^{16}$

As regards the therapy, we have used: $23 \mathrm{G}$ needles $(0.6 \times 30$ $\mathrm{mm})$ or $22 \mathrm{G}$ needles $(0.7 \times 50 \mathrm{~mm}) ; 20 \mathrm{~mL}$ syringes; ozone concentration: $10-15$ microgram $/ \mathrm{mL}$; quantity of ozone: $10 \mathrm{~mL}$ for each injected site. The treatment was biweekly for a total of 10 sessions.

We have included in the study ten subjects with piriformis syndrome, in compliance with the following exclusion criteria: pharmacological treatment with anti-inflammatory and/or muscle relaxants within 15 days prior to treatment; infiltration therapy with corticosteroids in the piriformis muscle within 30 days prior to treatment; patients undergoing orthopedic surgery in the lower limbs in the previous six months, pregnancy and neoplasms. During the duration of treatment, the use of NSAIDs, painkillers and myorelaxants was prohibited as was to have undergone physical therapies both manual and instrumental.

The treatment was carried out on all subjects with oxygen ozone.

The parameters were evaluated at time zero (T0; before treatment), at half of the therapy cycle (T1; 5 sessions), at the end of therapy (T2; 10 sessions), and 30 days later (T3).

The outcome values have been defined by means of: visual analog scale (VAS) for an assessment of subjective perception of pain; baropodometric examination to assess the distribution of static loads and load variations in the affected lower limb; any decrease in the positive results of performing the two more frequent clinical tests for the diagnosis of the piriformis, i.e. Freiberg test and of Peace and Nagle test. The reference values were: 0 , in the absence of pain, 1 in the presence of average pain, and 2 in the presence of severe pain.

\section{Results}

All patients have gained benefits in the evaluations carried out.

As far as the VAS scale is concerned: there was a reduction in the average value at the input from 9.1 to 5.6 at mid-treatment and 2.2 at the end. Follow up at 30 days fell to 0.4 .

As far as the baropodometric examination is concerned, the mean percentage of support of body weight on the ipsilateral lower limb to the piriformis syndrome showed a significant increase in the ability to load on the affected limb: 42.6 T0.46.5 T1.49.1 T2. On the contrary, with follow up there is a 50.4 that shows a certain return of postural equilibrium.

Also regarding the average performance over time of the tests of Freiberg, and of Peace and Nagle, an average of 2.5 and 2.3 was found, while an average of 2.5 and 2.3 was recorded in follow up, values close to $0,0.3$ and 0.1 .

\section{Conclusions}

The use of oxygen ozone in the treatment of pathologies such as the piriformis syndrome can be indicated with great favor thanks to the absence of side effects and/or secondary effects, the practicality of use, the speed with which positive results can be obtained, and above all the extent of clinical improvement. This can be considered a real healing that allows a very rapid and lasting functional recovery.

\section{References}

1. Parziale JR, Hudgins TH, Fishman LM. The piriformis syndrome. Am J Orthop 1996;25:819-3.

2. Durrani Z, Winnie AP. Piriformis syndrome: An undiagnosed cause of sciatica. J Pain Symptom Manage 1991;6:374-9.

3. Pecina M. Contribution to the etiological explanation of the piriformissyndrome. Acta Anat 1979;105:181-7.

4. Hallin RP. Sciatic pain and the piriformis muscle. Postgrad Med 1983;74:69-72.

5. Yeoman W. The relationship of arthritis of the sacro-iliac joint to sciatica. Lancet 1928;2:1119-22.

6. Robinson D. Piriformis muscle in relation to sciatic pain. Am J Surg 1947;73;355-8.

7. Beason LE, Anson BJ. The relation of the sciatic nerve and its subdivisions to the piriformis muscle. Anat Record 1937;70:1-5.

8. Cameron HU, Noftal F. The piriformis syndrome (editorial). Can J Surg 1988;31:210.

9. Chen WS. Sciatica due to piriformis pyomyositis. J Bone Joint Surg 1992;74:1546-8.

10. Hallin RP. Sciatic pain and the piriformis muscle. Postgrad Med 1983;74:69-72.

11. Bocci V. Ozone as a bioregulator. Pharmacology and toxicology of ozonetherapy today. J Biol Regulat Homeost Agent 1996; $10: 31-5$

12. Bonetti M, Valdenassi L. Oxygen-Ozone Therapy in percutaneous treatment of disk hernias. Unconventional medicine at the beginning of the Third Millenium, time for integration. Pavia, Italy: S. Maugeri Foundation, IRCCS Pavia; 1998.

13. Richelmi P, Valdenassi L. Aspetti biochimici ed implicazioni tossicologiche in Ossigeno Ozono Terapia. Attualità e prospettive in terapia antalgica. Ed. E.S.M.; 1995.

14. Valdenassi L, Bonetti M, Richelmi P, et al. L'ossigeno-ozono terapia nella medicina fisica e riabilitativa. In: Valobra GN (ed.) Trattato di medicina fisica e riabilitazione. Turin, Italy: UTET; 2000. pp. 1355-60.

15. Valdenassi L, Richelmi P, Franzini M. L'ossigeno-ozonoterapia nell'insufficienza venosa cronica: studio clinico di efficacia e tollerabilità. Flebologia 1995;6:7-14.

16. Valdenassi L, Richelmi P, Bonetti M, et al. Studio sperimentale sulla stabilità dell'ozono nelle usuali condizioni di utilizzo. Proc. of World Congress on Oxygen Ozone Therapy-Tertium Millenium, March 11-13, 1999, Verona, Italy. 